[Agr. Biol. Chem., Vol. 25, No. 9. p. 735 736, 1961]

\title{
Microflora in Raw Starch and Prevention Mechanism for Deterioration of Raw Starch by Use of Sodium Dodecyl Benzene Sulfonate
}

Sir:

Addition of dodecyl benzene sulfonate (D.B.S.) to raw starch was found to be effective for complete inhibition of its deterioration and the storage for long period without loss and deterioration has become possible.

As the deterioration mechanism of starch has not been clarified entirely, studies have been made on the fermentation products in deteriorated starch and it was found that the butyric acid fermentation was the main cause. The result of tracing of microflora in stored starch indicated that there were many kind of gram-positive organisms, such as Bacillus, Clostridium, and Lactbacillus at the initial stage, but those disappeared gradually due to the lowering of $\mathrm{pH}$ by fermentation. A colony isolated from starch was inoculated on sterile raw starch and studies on the reproducibility of deterioration confirmed that Clostridium butyricum was the main organism related to this deterioration.

Although the raw starch stored with the addition of D.B.S. did not show deterioration, analysis of microflora indicated the presense of gram-negative organisms, such as Aerobacter aerogenes and Pseudomonas.

Bacteriostatic activity of D.B.S. on colonies isolated from starch as well as other organisms has been investigated. It was found that this substance had growth inhibitory action for gram-positive organisms in dilution of $1 /$ $20,000 \sim 1 / 50,000$, but it had no inhibitory action for gram-negative organisms in dilution at $1 / 1,000$. From the fact that the permiability of cell walls or the combining power of cells with dyes is high in gram-positive organisms, it is considered that D.B.S. acts on the organisms in a similar mechanism.

The differences in the growth inhibitory action of D.B.S. against Clostridium butyricum by the difference of $\mathrm{pH}$ range have been investigated. It was found that the minimal growth inhibitory concentration was $2.5 \mathrm{r} / \mathrm{ml}$ at $\mathrm{pH} 4.5$, and $5 \gamma / \mathrm{ml} \sim 10 \gamma / \mathrm{ml}$ above $\mathrm{pH}$ 5.5. Thus, D.B.S. showed a stronger growth inhibitory action in acidic side. This fact can be assumed also from the result of preceeding report that D.B.S. combines well with proteins in acid range.

Bactericidal activity of D.B.S. on Clostridium butyricum in nonvegetative stage of growth has been investigated and it was found that the bactericidal velocity coefficient was K. $1,000 \gamma / \mathrm{ml}=1.26$ and $\mathrm{K} .100 \gamma / \mathrm{ml}=0.40$, and the exponent, $n$, of dilution coefficient, was $1 / 2$. Therefore, discussion of bactericidal activity of D.B.S. in comparison with well known phenol coefficient is meaningless.

The bactericidal activity of D.B.S. in the vegetative stage of growth of Clostridium butyricum has been investigated and it was found that addition of $5 \mathrm{r} / \mathrm{ml}$ and $10 \mathrm{r} / \mathrm{ml}$ of D.B.S. showed bactericidal action and decreased the number of living organisms. There was a complete growth inhibition in $10 \mathrm{r} / \mathrm{ml}$ treatment and there was no increase in total number of organisms. Addition of $50 \mathrm{r} / \mathrm{ml}$ of D.B.S. in the logarithmic growth phase of the control showed clear decrease of total number of organisms as well as number of living organisms, with the indication 
of bacteriolysis.

Addition of D.B.S. solution to vegetable cells of Clostridium butyricum caused the permiation of cellular contents, such as proteins and nucleic acid, due to bacteriolysis.

These experiments indicate that D.B.S. is an effective bactericide for Clostridium butyricum as well as for many gram-positive organisms present in starch during its storage for long period of time and is effective for preven- tion of deterioration of starch. This was attributed to the combination of D.B.S. and proteins of the organisms to give a metaprotein by bacteriolysis.

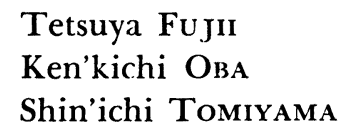

Received August 1, 1961 